\title{
Heart
}

\section{Interview: Professor Peter Weissberg, Medical Director of} the BHF

\begin{tabular}{|r|l|}
\hline Journal: & Heart \\
\hline Manuscript ID & heartjnl-2016-310084 \\
\hline Article Type: & Cardiology in focus \\
\hline Date Submitted by the Author: & 01 -Jun-2016 \\
\hline Complete List of Authors: & Rudd, James; University of Cambridge, Division of cardiovascular medicine \\
\hline Keywords: & CARDIAC PROCEDURES AND THERAPY \\
\hline Abstract: & - \\
\hline & \\
\hline
\end{tabular}

\section{SCHOLARONE"}

Manuscripts 
Dr James Rudd, Heart's Digital Media Editor, interviewed Professor Peter Weissberg, Medical Director of the British Heart Foundation (BHF), in May 2016. As the largest independent funder of cardiovascular research in the UK (around $f 100$ million annually), Peter has sage advice for young researchers considering a career in cardiovascular science. He looks back at some highlights from his 12 years at the BHF. Finally, Peter explains why there has never been a better time to consider a career in cardiovascular research.

The interview was released as an audio podcast, which is available online via iTunes and at heart.bmj.com. This is an edited transcript.

\section{Biography}

- Professor Weissberg underwent most of his early clinical training in and around Birmingham, before specialising in cardiology and being appointed Lecturer in Cardiovascular Medicine in the University of Birmingham in 1983.

- Between 1985-87, Professor Weissberg was Medical Research Council Travelling Fellow at the Baker Medical Research Institute in Melbourne, Australia where he developed his interest in vascular smooth muscle cell biology.

- On returning to the UK in 1988, Professor Weissberg began his long relationship with the BHF when he was awarded a BHF Senior Research Fellowship (Honorary Consultant Cardiologist) in the Department of Medicine in Cambridge. In 1994 he was appointed to the first BHF Chair of Cardiovascular Medicine in Cambridge.

- Professor Weissberg has also been an Honorary Consultant Cardiologist to Addenbrooke's Hospital since 1988 and was Director of Cardiology at Addenbrooke's Hospital for 13 years.

- His research focused on the cell and molecular biology of atherosclerosis and his group developed new clinical imaging techniques to study the cell biology of atherosclerosis in patients with cerebrovascular disease.

James Rudd: Peter, having been the Medical Director of the largest independent charity funding cardiovascular research in the UK for the last 12 years, do you have any highlights that you could tell us about, such as any research funding that has made a big impact nationally or internationally?

Peter Weissberg: There are a couple of things that l'd like to draw attention to. One is the fact that we are the biggest funder in Europe so we have enormous leverage in terms of what we can do in cardiovascular science, which is one of the reasons that I came to the BHF in the first place. One of the things I am most proud of is our research centres of excellence; I think they have really delivered what we hoped, which was a new generation of young scientists who are now fully immersed in cardiovascular science. We have also got a lot of non-biological scientists from the physical sciences engaged in cardiovascular science in a way that they weren't before we set those up.

In terms of impacts, you have to look back further than just 12 years. My association with the BHF has been over several decades, because I was funded by the BHF for most of my career before I became Medical Director. What has been really gratifying to see is that research which BHF was funding 20 years ago - such as work by Hugh Watkins identifying the genes for hypertrophic cardiomyopathy and by Steve Humphries doing similar work for familial hypercholesterolaemia - is now entering mainstream clinical practice. BHF is funding genetics nurses for familial hypercholesterolaemia and inherited heart 
conditions in order to catalyse this by putting money into it. It's been great to see some of the basic science that I was aware of when I was doing research myself coming into the primetime.

JR: As you say, some of these discoveries - from the initial moment of discovery to actually getting into guidelines and getting funding - take a long time.

PW: And a lot of effort, a lot of pushing, so it's nice to see it all come together.

JR: What about the research landscape in 2016 and over the next five years? You've got your finger on the pulse of what the government is thinking and other funding agencies are planning. Is it a good time to get into cardiovascular research?

PW: I think it's a good time to be getting into and staying in research. The last two successive UK governments have been pretty good at funding fundamental science and universities, and maintaining funding in trying times. I think biosciences in the UK are very strong. BHF is in the fortunate position, alongside Cancer Research UK, of being a very well-funded and effective charity that can offer money in a way that charities in other countries cannot, except for maybe the American Heart Association.

I would encourage any young scientist or clinician who is thinking of going into research, because the one thing that they won't have to worry about in the immediate future is the funding landscape, particularly in the cardiovascular arena because it's in robust health. We have fairly big plans for the next five to ten years to increase income and our research spend; we are planning on spending at least $f 100$ million each year for the next five years, which is a lot of money.

JR: How does that compare with what you've been spending recently? Is that a significant uplift?

PW: Ever since I have been at the BHF research funding has increased year on year; going back several years we were funding about $£ 40-50$ million per year and it has grown steadily. For the last two to three years we have spent $£ 80-100$ million, this last financial year we were at $£ 107$ million (which was all planned spend), and we have plans to spend similar amounts over the next five years.

JR: You have some different schemes as well, in terms of funding researchers?

PW: We refreshed our strategy so that we have a template on which to hang our objectives. A lot of it is business as usual (with some tweaks to make), but we are really trying hard to encourage and retain women in science, both medical science and laboratory science. To an extent, the medical side is down to the career choices made by women, and cardiology is a specialty that is chosen by relatively few women so we have a problem there. In basic science we start off with a surfeit of very bright female PhD students, and in fact there are more successful women than men, but very quickly that pendulum goes the other way and very few women are there when it comes to the more senior fellowships. That's a massive lot of talent and we're trying to do something to reverse that.

The other area that the BHF has perhaps been a little slower in getting into than some others is the translational space - getting laboratory research that has promise to deliver a new drug, drug target or diagnostic through that process of getting the early rounds of funding so that it can achieve proof of principle that will attract the bigger funders. That's something that we only launched about two years ago but has been very successful and we are going to grow that if we can. 
The third area that I think will grow in the immediate future is clinical research and clinical trials. As we grow our income, we can afford to spend more on larger clinical trials so we have set up a new clinical studies committee that will start early in 2017.

JR: Finally, your successor has just been announced - Professor Sir Nilesh Samani from the University of Leicester. Do you have any advice for him as he steps into your shoes?

PW: There are two things really. One is that there is a big culture change in going from a university environment to a big charity like BHF that is run like a corporate company, in terms of management and people development and things like that. On the other hand, it's incredibly liberating - having worked for all of one's career in a health service that is strapped for cash and a university sector where you really struggle to try to do something new because of the funding situation - to come to an organization where you say "I have a few good ideas" and they say "Great, we'll try and raise the money to fund them". That's enormously exciting. 


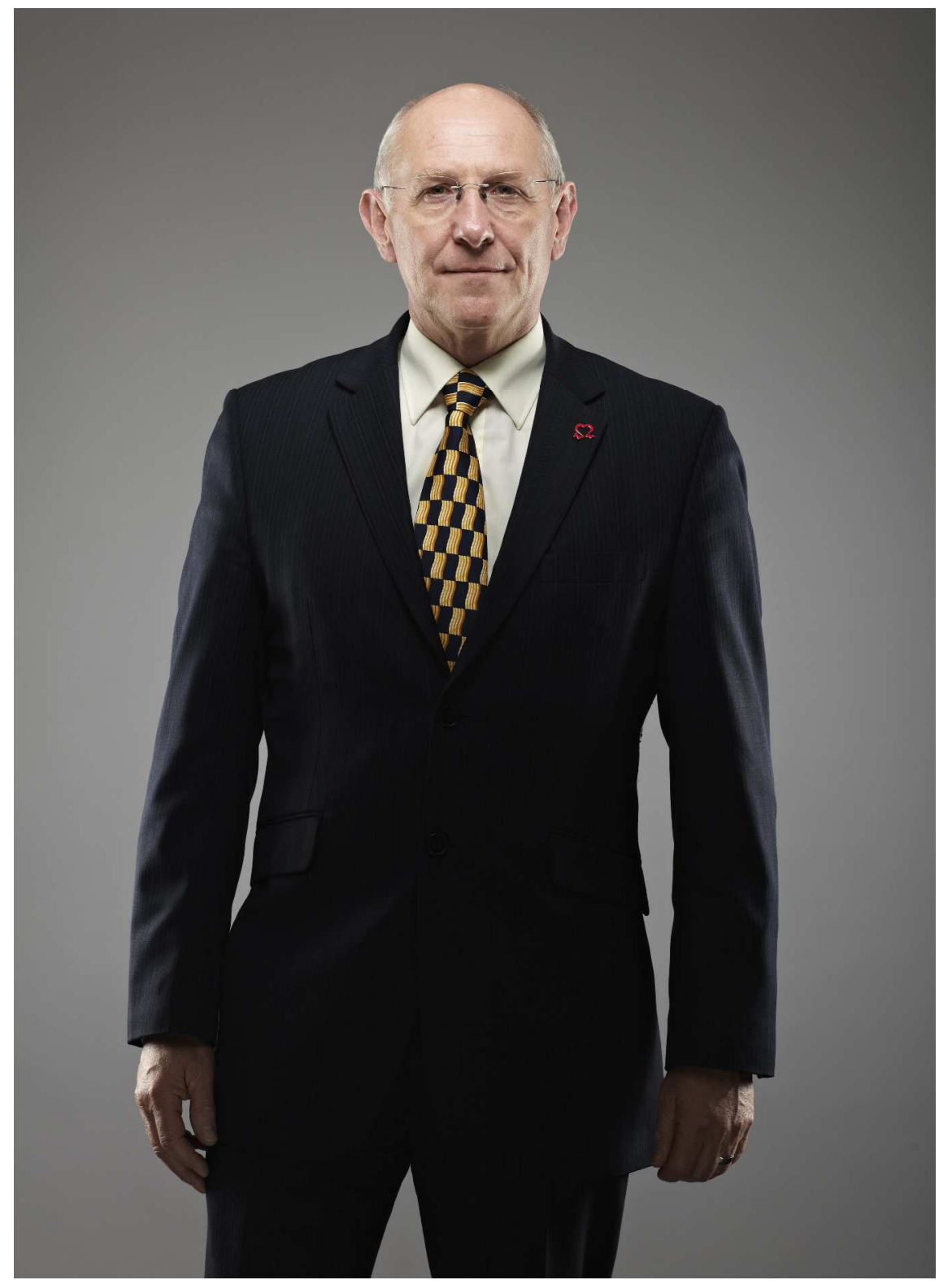

$312 \times 429 \mathrm{~mm}(300 \times 300$ DPI $)$ 